\title{
CHAPTER $4^{17}$
}

\section{Intergenerational inequality}

This chapter explores an aspect of inequality which is receiving increasing attention in both the domestic and international policy debate: intergenerational inequality, that is of inequality between generations. ${ }^{18}$ Such inequalities have come into sharp focus since the onset of the COVID-19 pandemic, with research highlighting the disproportionate impact in the labour market on younger workers and those from minority backgrounds (Adams-Prassl et al., 2020; Crossley et al., 2021; Enright et al., 2020).

Figure 4.1 shows that job losses have also fallen most heavily on younger workers in Ireland. The series plot the change in the employment rate for different age groups over 2020, excluding those absent from paid work because of COVID-19. ${ }^{19}$ These show employment rates fell by almost 60 per cent and 50 per cent respectively for those age 15-19 and 20-24 respectively in the second quarter of 2020, compared to 25 per cent for those aged 25-29 and 55+, and 20 per cent for other age groups.

\section{FIGURE 4.1 CHANGE IN EMPLOYMENT RATE FROM PEAK (Q1 2020=100)}

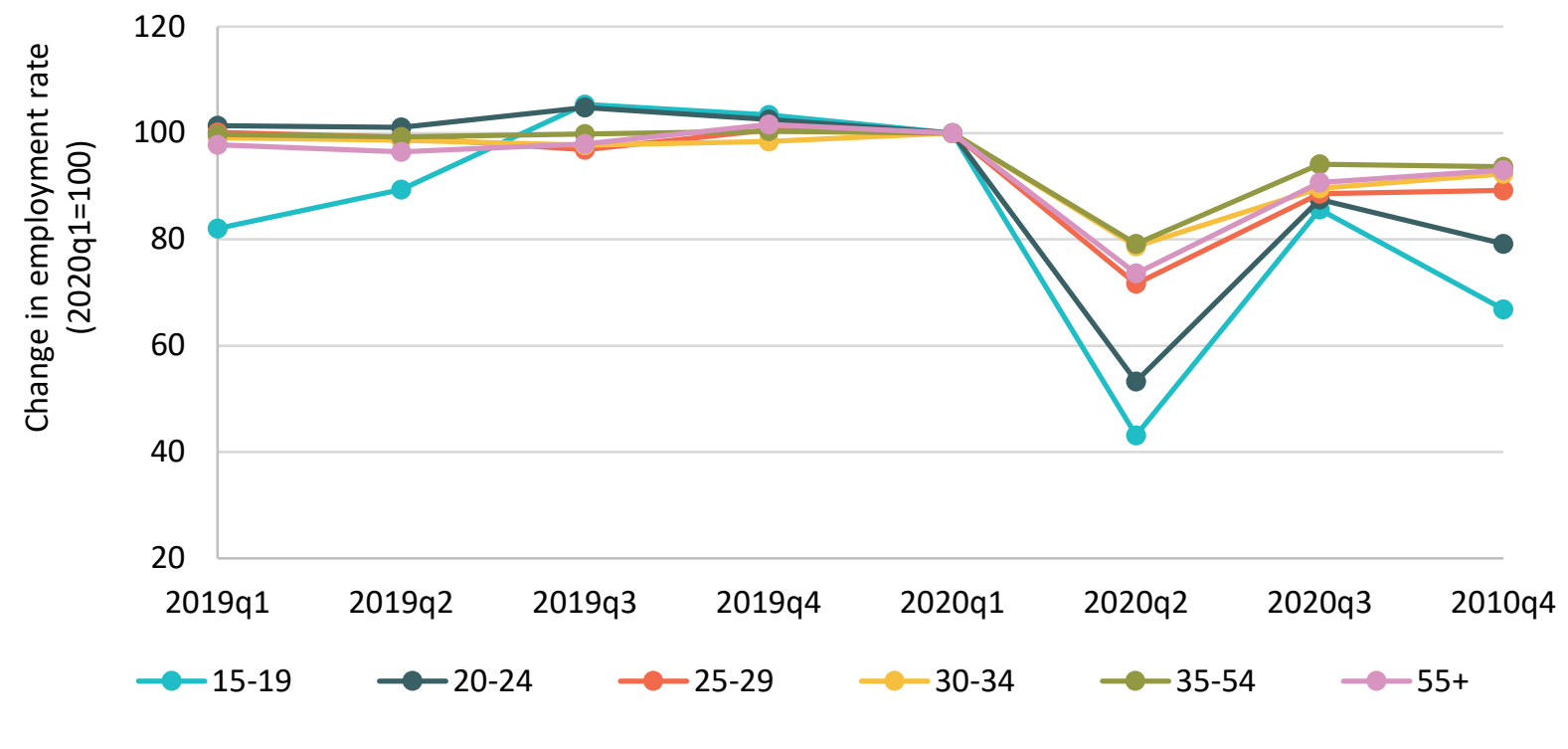

Sources: Authors' calculations using Labour Force Survey Research Microdata Files (LFS RMF).

Note: Employment rate calculated using ILO definition excluding those reporting absences due to COVID-19.

17 https://doi.org/10.26504/bkmnext412_chapter4.

18 See, for example, Nugent (2020); Cribb (2019); Kurz et al. (2019); Resolution Foundation (2018). The term is sometimes also used to refer to the transmission of disadvantage within families, or social mobility.

19 This differs from the definition of employment used by the CSO which includes those who expect to return to their employer in the next three months or receive more than 50 per cent of their previous salary, creating clear problems for the measurement of employment during a pandemic. Roantree (2020a) shows the same pattern holds examining claims for the Pandemic Unemployment Payment. 
Although employment for all age groups recovered significantly in the latter half of 2020 - reflecting the lifting of public health restrictions over the summer and around Christmas - younger workers have remained most adversely affected, especially taking into account the fact that seasonal patterns of work typically lead to higher rates of employment for younger workers over the summer and at Christmas. Indeed, employment remained a third below its pre-pandemic level for those age 15-19, a fifth below for those age 20-24, and 10 per cent below for those age 25-29, compared to 7 per cent for older age groups. As a result, there were an estimated 112,000 fewer 15-34 year olds in paid work in the final quarter of 2020 than a year earlier, compared to 93,000 fewer workers aged $35+$.

This disproportionate impact of job losses on young workers is in part because they are more likely to work in retail, hospitality, arts or leisure: sectors which have been most heavily affected by the public health measures necessary to suppress the spread of COVID-19 (Byrne et al., 2020). This is shown in Figure 4.2, which plots the share of workers in these sectors by age and birth cohort. A sharp age gradient in the likelihood of working in such vulnerable sectors is evident, with fewer than a fifth of workers age 40-60 doing so compared to more than a third of those in their early 20s. Figure 4.2 also shows that - like in the UK (Blundell et al., 2020) - the importance of these sectors for young adults has been growing across generations, with almost 40 per cent of workers born between 1985 and 1994 working in retail, hospitality, arts or leisure in their mid-20s compared to around 20 per cent of those born in the 1970s.

FIGURE 4.2 SHARE WORKING IN RETAIL, HOSPITALITY, ARTS OR LEISURE, BY AGE AND BIRTH COHORT

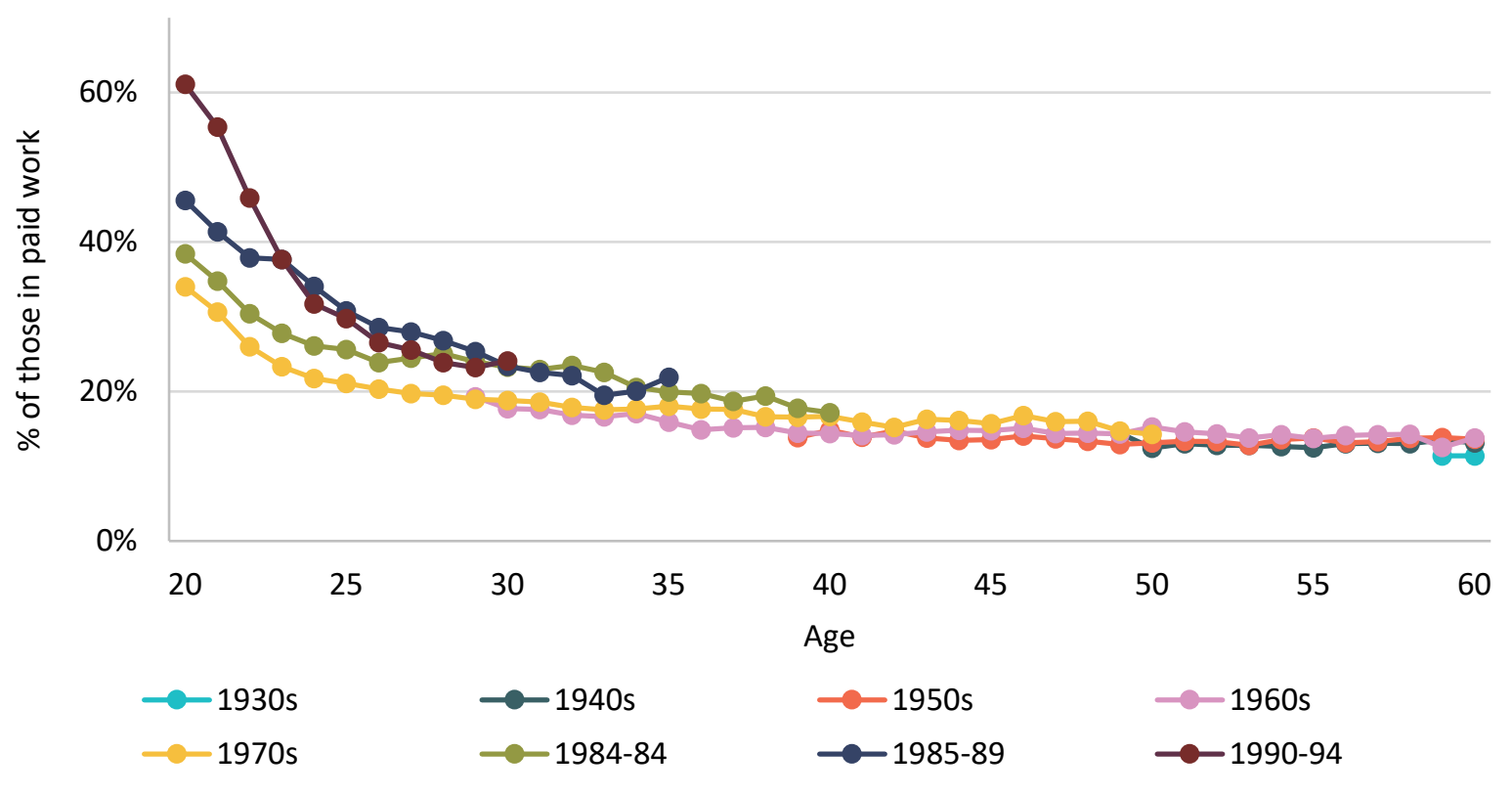

Sources: $\quad$ Authors' calculations using Labour Force Survey Research Microdata Files (LFS RMF). 


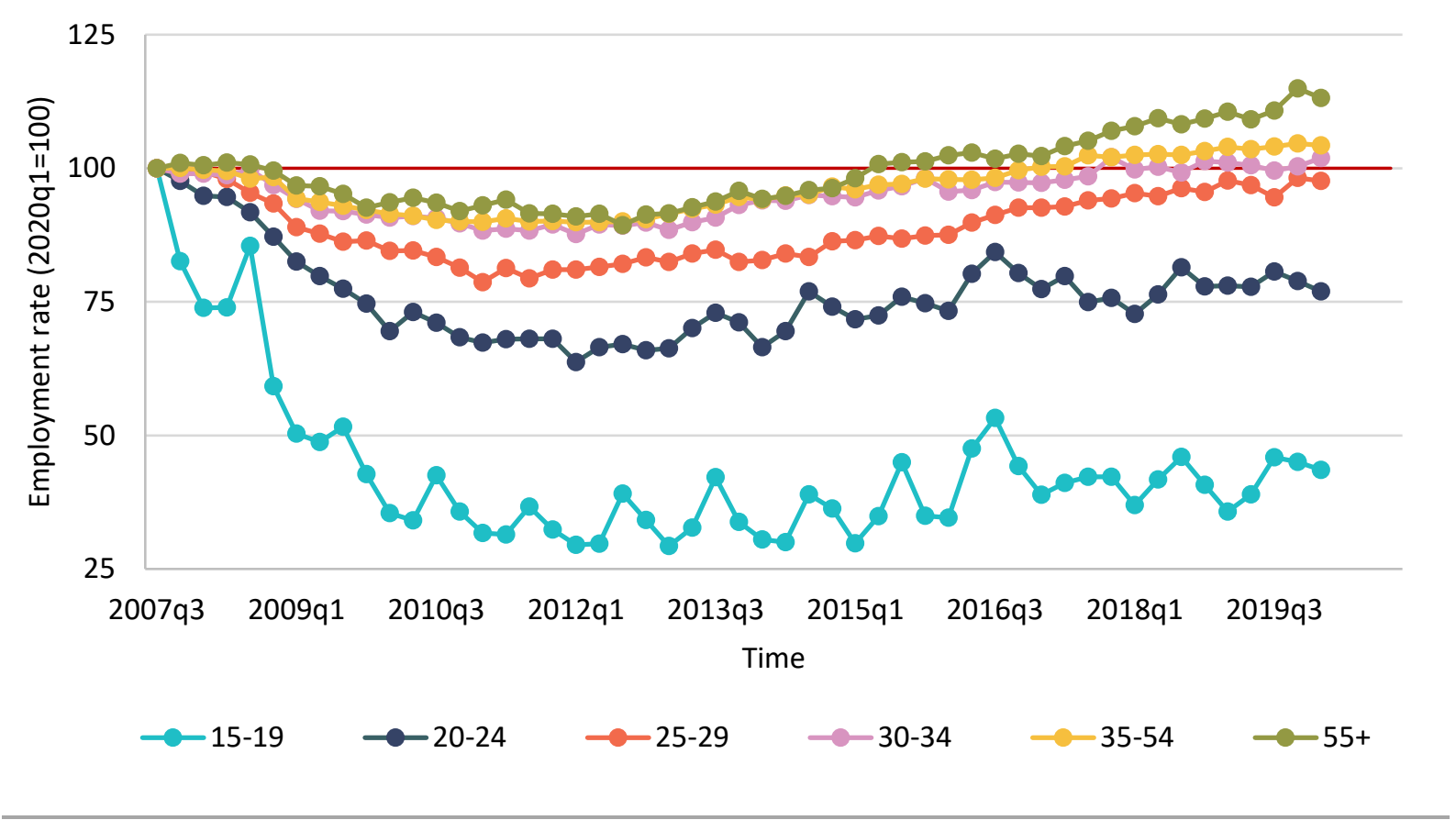

Sources: Authors' calculations using Labour Force Survey Research Microdata Files (LFS RMF).

Note: Employment rate calculated using ILO definition.

In addition to being more likely to work in these lockdown susceptible sectors, Redmond and McGuinness (2020) show that young workers are significantly less likely to have previously worked from home conditional on their occupation. This suggests their scope for working from home may be more limited than older workers in the same jobs, a factor which could also help explain the greater decline in employment among younger adults shown in Figure 4.1.

Young adults were also disproportionately affected by job losses over the course of the Great Recession. This is shown in Figure 4.3, which (like Figure 4.1) plots the change in employment rates by age relative to their pre-crisis peak (in this case Q3 2007). Employment rates declined by around two-thirds from peak to trough for those age 16-19, a third for those age 20-25 and a fifth for those age 25-29, compared to around 10 per cent for older workers. Moreover, Figure 4.3 also shows that employment rates were only just approaching their pre-crisis level for 25-29 year olds on the eve of the pandemic and were still far below the rates for those under 25, despite having recovered for other age groups by 2017 at the latest.

Declines in employment for young adults need not have negative consequences if they are the result of a switch from employment to increased educational participation. Indeed, Bercholz and FitzGerald (2016) raise the prospect of a future boost to productivity and earnings arising from the fall in employment and rise in human capital investment over the crisis. 


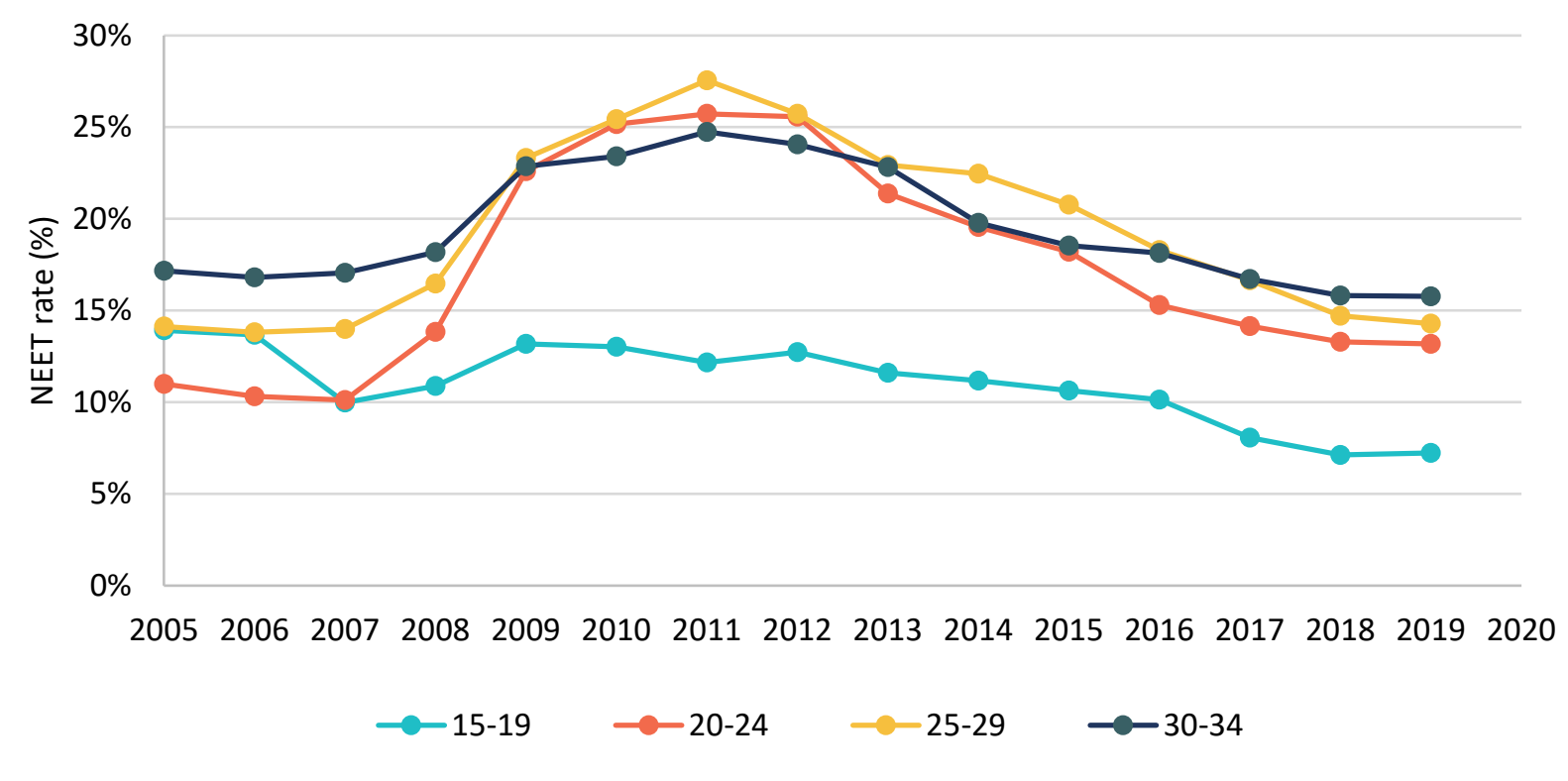

Sources: Authors' calculations using Labour Force Survey Research Microdata Files (LFS RMF).

Note: $\quad$ Not in paid work during the LFS reference week nor a student or apprentice in regular formal education during the last four weeks (excluding those temporarily on holidays).

However, Figure 4.4 - which plots the 'not in employment, education or training' (NEET) rate for the youngest four age groups considered above - suggests a less sanguine development. It shows that while the NEET rate among those age 15-19 was only temporarily elevated (and indeed by 2017 had recovered to a lower level than in 2007, indicating some substitution from employment to education), this was not the case for those in their 20s. Rather, the NEET rate for those aged 25-29 doubled from 14 per cent in 2007 to 28 per cent in 2011 and had only just returned to its pre-crisis level on the eve of the pandemic. For those age 20-24 NEET rates rose even more sharply, from 10 per cent in 2007 to 26 per cent in 2011, and remained stubbornly above its pre-crisis rate at 13 per cent on the eve of the pandemic. This amounts to around 30,000 more 20-24 year olds not in education, employment or training than one would expect had the labour market fully recovered for this age group; a figure which would likely be higher still if it were not for the impact of emigration which Conefrey (2013) shows was disproportionately comprised of young adults over this period.

Such high and sustained levels of economic inactivity should be of concern to policymakers, not just for the cost they represent in terms of un(der)utilised labour but also the potential 'scarring' effect they may have on young adults entering the labour market. A growing body of economic research finds entering a depressed labour market has large, negative impacts on earnings and employment that can take $10-15$ years to fade. ${ }^{20}$ Adverse initial labour market conditions have also been 
found to have persistent effects on the likelihood of engaging in criminal activities, experiencing divorce and even on support for redistribution. ${ }^{21}$

\section{FIGURE 4.5 AVERAGE REAL WEEKLY EARNINGS, BY AGE AND BIRTH COHORT}

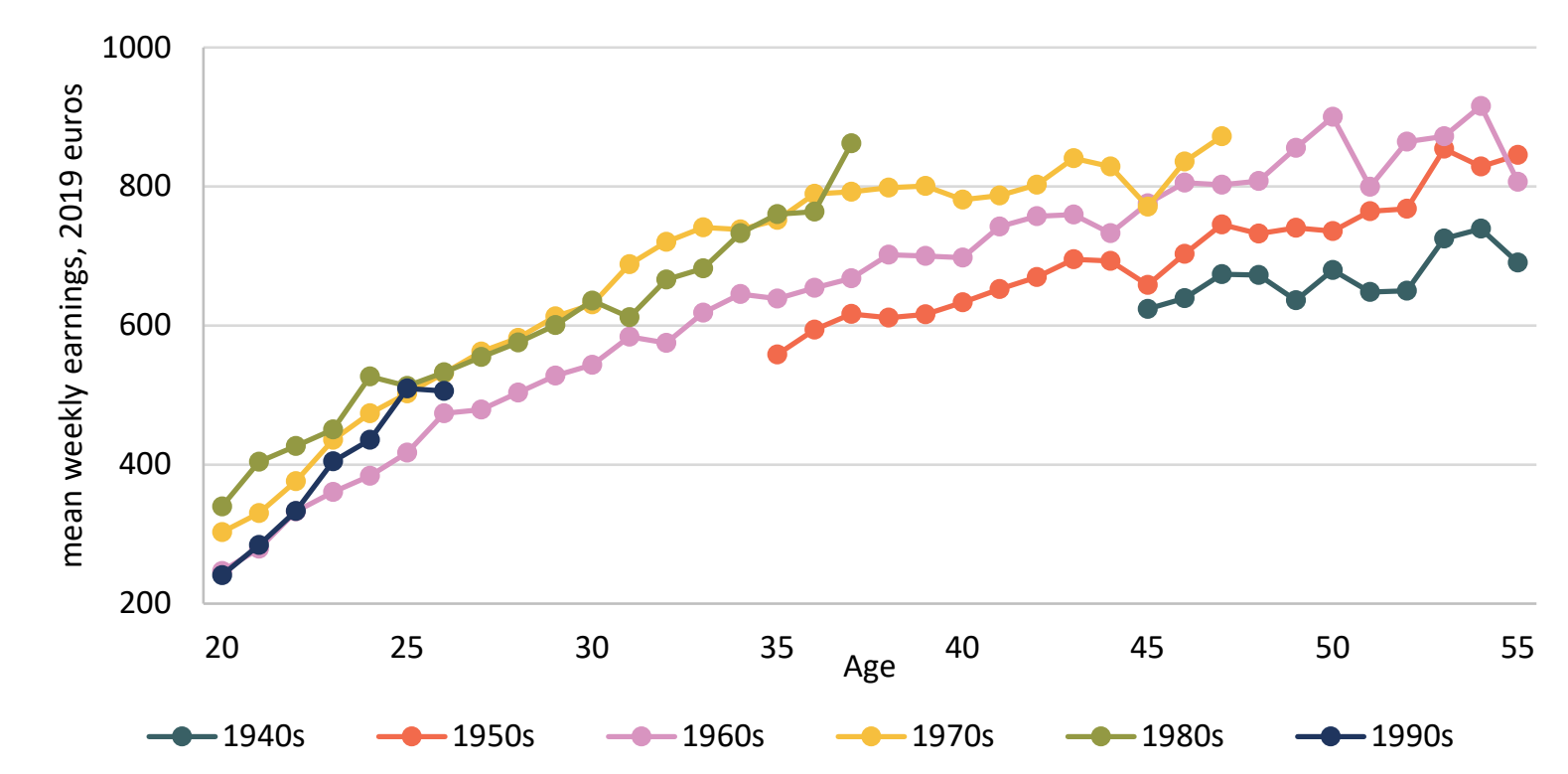

Sources: Authors' calculations using the Survey of Income Distribution, Poverty and Usage of State Services; the Living in Ireland survey; and the Survey of Income and Living Conditions.

Note: $\quad$ Average (mean) real weekly earnings by age and year of birth cohort for those in paid work, deflated by the CPI.

Figure 4.5 presents early evidence consistent with (and indeed suggestive of) the Great Recession having had such 'scarring' effects on the earnings of young adults in Ireland. ${ }^{22}$ It shows strikingly that - adjusted for inflation - average weekly earnings for workers born in the 1990s were no higher than for those born in the 1960 s at ages 20 to 22, and had by age 26 yet to surpass that of either the 1970s or 1980s cohort. This amounts to a halt in the patterns of earnings growth that have historically been observed across generations both in Ireland (as shown above) and internationally (e.g. Cribb, 2019; Kurz et al., 2019).

However, Figure 4.5 also shows that a more widespread stagnation in earnings growth has ensued from the Great Recession, with average earnings for those born in the 1980 s no higher from age 25 to 35 than for those born in the 1970s. This is despite those born in the 1980s seeing earnings that were on average substantially higher at the beginning of working life than they were for those born a decade earlier, and the earnings of the 1970s cohort also being affected by the Great Recession in their mid- to late-thirties. Indeed, those born in the 1980s and 1990s stand out as being the first of the generations covered by our data not to 
experience consistently higher earnings than that born a decade earlier, with average earnings for those born in the 1970s and 1960s falling below that of previous cohort at only one age apiece (45 and 55 respectively). Similar stagnation in earnings growth across generations has also been documented in Britain by Cribb (2019) and in the United States by Kurz et al. (2019).

In addition to poor prospects in labour market, a growing share of young adults are facing high housing costs. ${ }^{23}$ Figure 4.6 illustrates this, plotting the share paying more than 30 per cent of their disposable income in housing costs - a metric of housing affordability proposed by Corrigan et al. (2019) - each month by age and birth cohort. This shows that more than a fifth of those born in the 1980s were paying more than 30 per cent of their disposable income on housing at age 30 compared to 13 per cent of those born in the 1970s. While our data do not extend back far enough to cover previous generations at age 30 , less than 10 per cent of those born in the 1960s spent more than 30 per cent of their disposable income on housing around age 40 , compared to 13 per cent of those born in the 1970 s.

FIGURE 4.6 \% PAYING >30\% OF DISPOSABLE INCOME IN HOUSING COSTS, BY AGE AND BIRTH COHORT

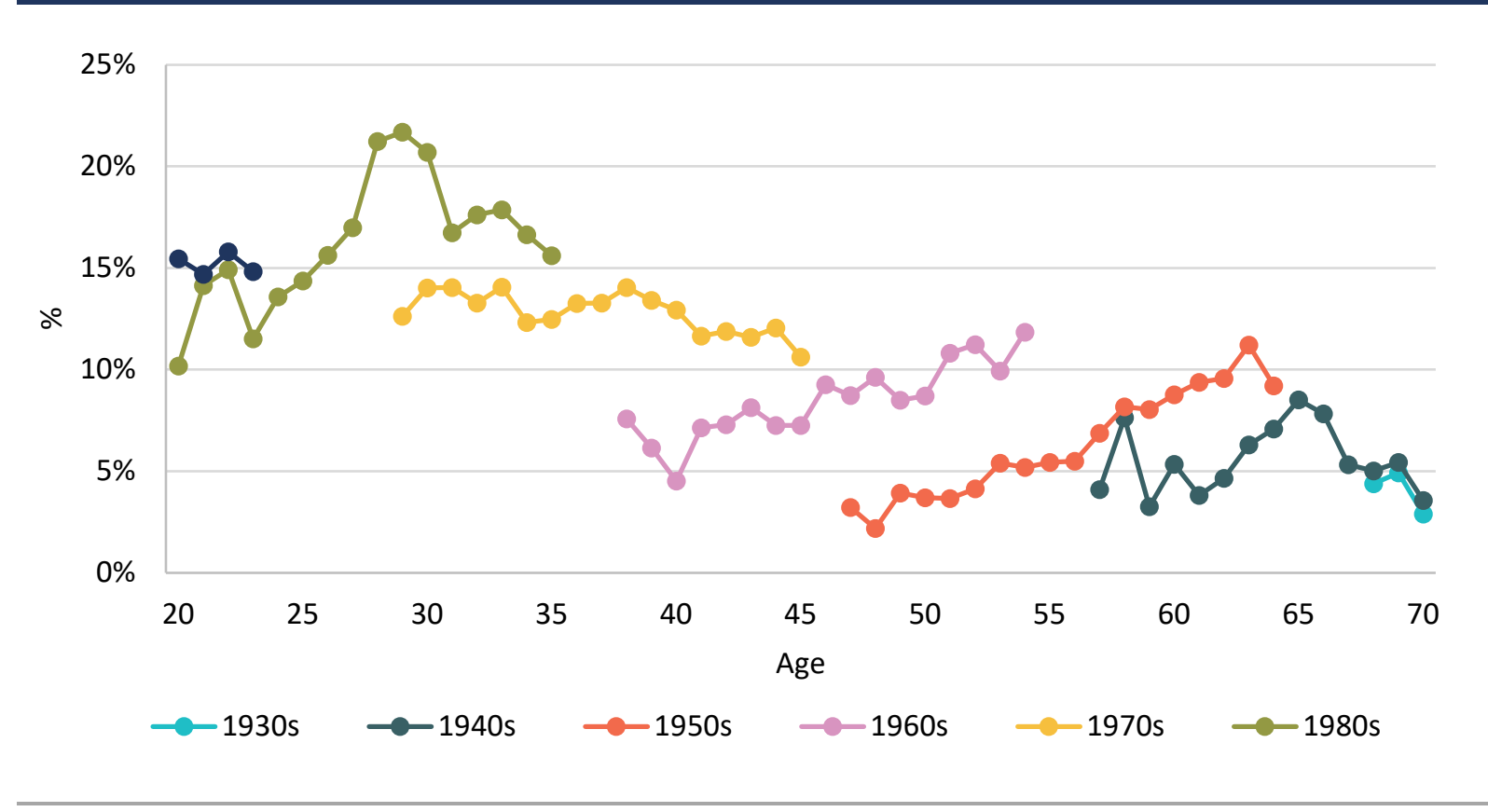

Sources: Authors' calculations using the Survey of Income and Living Conditions.

Note: Housing costs include rental payments for tenants and mortgage interest payments for owner-occupiers (gross of housing benefits and net of tax relief respectively) along with the cost of utilities, structural insurance, taxes on dwellings, regular maintenance and repairs payments and mandatory services and charges.

23 We use the Eurostat definition of housing costs from SILC which includes rental payments for tenants and mortgage interest payments for owner-occupiers (gross of housing benefits and net of tax relief respectively) along with the cost of utilities, structural insurance, taxes on dwellings, regular maintenance and repairs payments and mandatory services and charges. 


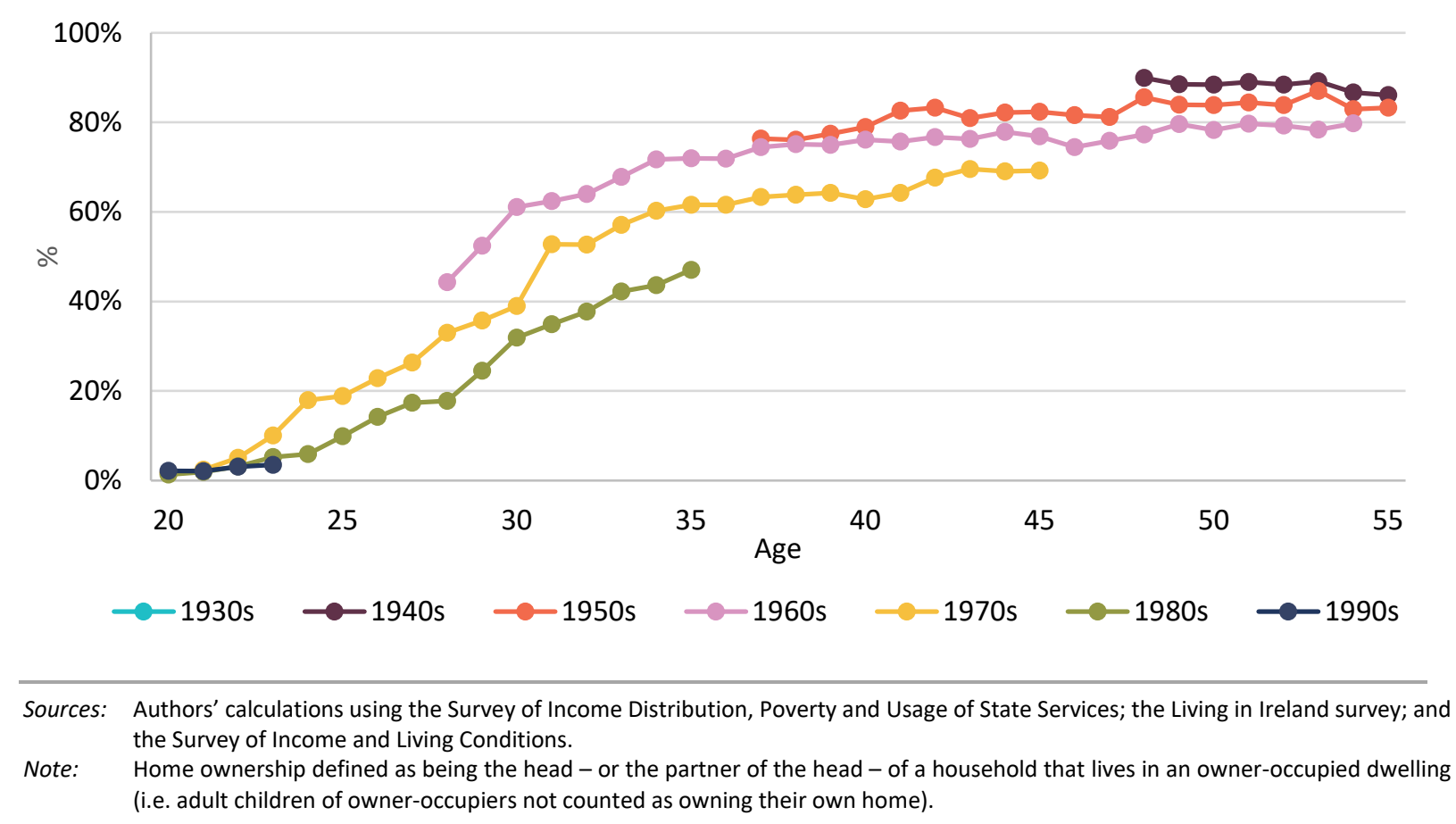

This change is closely related to a sharp decline in home ownership rates among recent generations, as is shown by Figure 4.7. While more than 60 per cent of those born in the 1960s lived in a home they or their partner owned by age 30, this had fallen to 39 per cent for those born in the 1970s and 32 per cent for those born in the early 1980s. While there may be some degree of catch-up at later ages (in part reflecting changes in patterns of family formation), the figure shows that rates of home ownership have tended to level off by age 45 for previous cohorts, with each successive generation less likely to live in owner-occupied housing than the last.

Although tenure-neutral housing affordability has been a longstanding objective of (officially stated) Irish policy, research has consistently found that affordability issues are most acute in the private rented sector (e.g. Blackwell, 1989; Fahey, 2004; Fahey et al., 2004; Corrigan et al., 2019; O'Toole et al., 2020). A consequence of declining rates of home ownership across generations is therefore that increasing numbers of young adults are exposed to the private rental market, where existing affordability issues have been exacerbated by rapidly rising rents in recent years. 


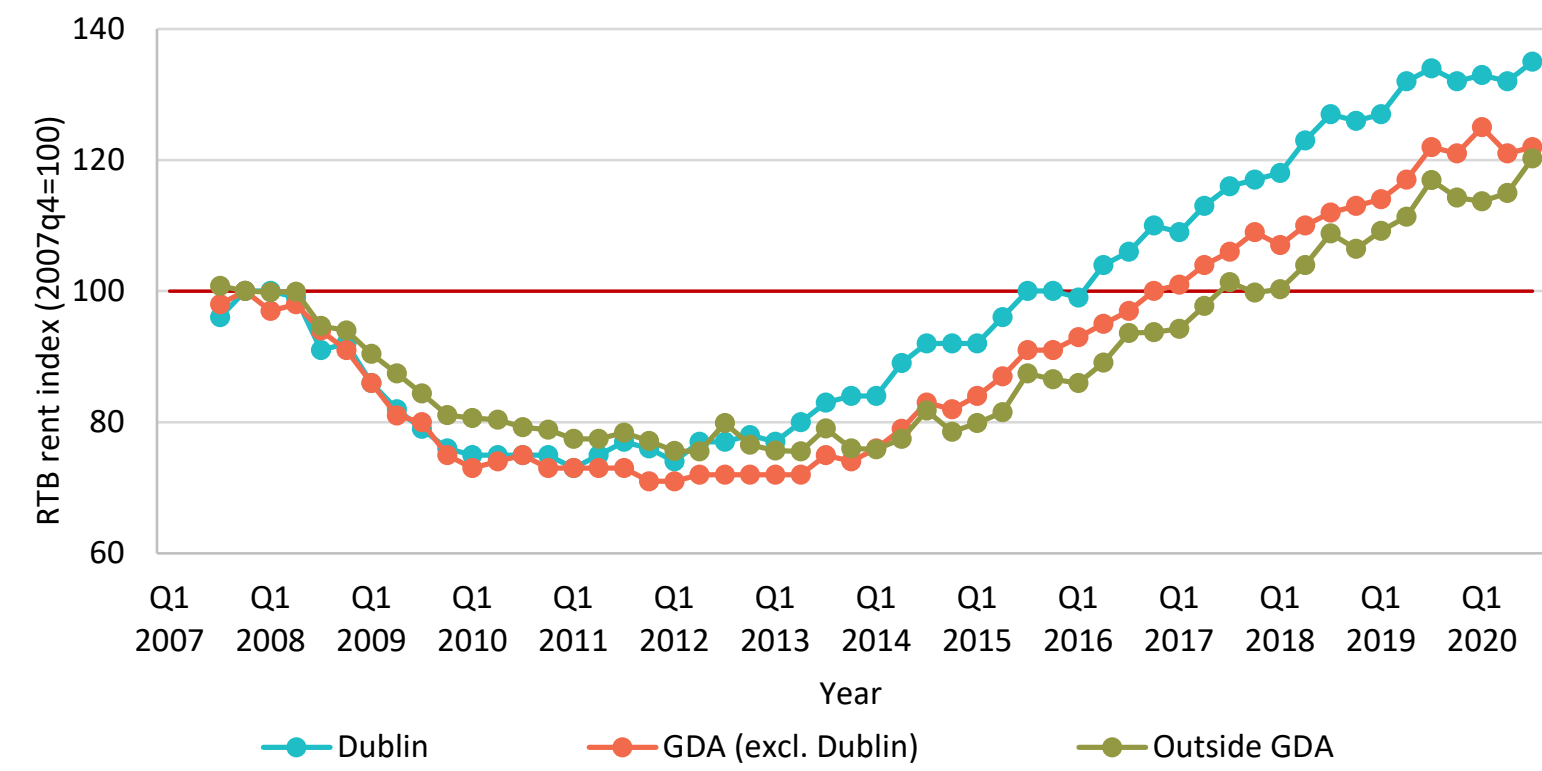

Source: Residential Tenancies Board (2020).

Note: $\quad$ Figure shows ESRI-RTB Rent Index of standardised rents.

This is illustrated in Figure 4.8, which plots changes in the Residential Tenancies Board (RTB) Rent Index since it began for four regions relative to their level in Q4 2007. While rents declined significantly over the course of the Great Recession, they have since regained and far surpassed their pre-crisis peak in all areas of the country. Rents have risen most sharply in Dublin, where they now stand 35 per cent above their Q4 2007 level and 85 per cent above their Q1 2011 trough. Other parts of the country have also seen significant increases in rent, with the indices for areas outside of Dublin all more than 20 per cent above their Q4 2007 level.

The combined effect of these developments is to cast a pall over the prospects of young adults and should be a cause of serious concern for society at large. While we have looked only at widening inequalities across generations in housing and the labour market, Cribb (2019) and Kurz et al. (2019) show these are even more pronounced for wealth in Britain and the United States respectively. While bequests are likely to mitigate some of this inequality in wealth across generations (with those born in the 1980s and 1990s receiving inheritances from their parents born in the 1950s and 1960s), Bourquin et al. (2021) show these are also likely to amplify inequality within generations (between those with richer and those with poorer parents).

As we discuss in the next chapter, one area where policy can help is ensuring the provision of high-quality active labour market programmes with sufficient capacity to cater for the numbers that will need them in the aftermath of the COVID-19 pandemic. Policies that act to tackle the root causes of high rents will also 
disproportionately benefit those younger adults who risk otherwise being left behind, especially those policies that act to increase the supply of housing. However, increasing housing supply significantly will take time and there may therefore be a case in the interim for examining whether the current of system of housing supports for low-income private renters (e.g. Housing Assistance Payment and Rent Supplement) is adequate. 